\title{
O QUE SERÁ DAS INSTITUIÇÕES DE EDUCAÇÃO SUPERIOR COMUNITÁRIAS E CONFESSIONAIS?
}

\author{
WHAT IS GOING TO HAPPEN TO COMMUNITY AND CHURCH \\ RELATED HIGHER EDUCATION INSTITUTIONS? \\ ¿QUE SERÁ DE LAS INSTITUCIONES DE EDUCACIÓN \\ SUPERIOR COMUNITARIAS Y CONFESIONALES?
}

VALDEMAR SGUISSARDi Prof. Dr. Titular (aposentado) da UFSCar e ex-professor do PPGE/Unimep

Resumo Este artigo visa contextualizar as levas de demissão de docentes da Unimep e de outras instituições de educação superior comunitárias e confessionais ocorridas no final de 2017. Visa também demonstrar que, apesar de especificidades próprias à gestão das instituições metodistas, via "Rede Metodista", isto faz parte de um fenômeno muito mais amplo que decorre de vários fatores presentes no país. Entre esses estão mudanças na produção (ajuste neoliberal), reforma do Estado, política de educação superior vigente, e o aprofundamento do que traduzem os neologismos mercadização, mercadorização e mercantilização da educação superior. Esse fenômeno apresenta alguns traços comuns ao que ocorre em países centrais e da periferia do capitalismo dominado pela racionalidade neoliberal, mas também revela outros, muito particulares e próprios, que diferem significativamente dos que vigem no exterior. Diante disso, conclui-se afirmando que a pergunta do título deste texto - o que será das instituições de educação superior comunitárias e confessionais? - precisa ser sempre reposta, seja para questionar a gestão dessas instituições de tão reconhecida importância no país, seja para denunciar os caminhos seguidos pela política de educação superior no Brasil, que está celeremente se deixando conduzir pela racionalidade neoliberal dominadora do mercado e do próprio Estado.

Palavras-chave: Instituições Comunitárias; Instituições Confessionais; MercantilizaÇão DA EDUCAÇ̃̃o SUPERIOR; POLÍtICA DE EDUCAÇ̃̃o SUPERIOR. 
Abstract This paper aims at showing the context within which a great many number of teachers of UNIMEP and other community and church related higher education institutions were fired by the end of 2017. It also aims to demonstrate that despite characteristics specifically linked to the management of Methodist institutions - established by the "Methodist Network" - this is part of a much wider phenomenon derived from several factors present in the Country. These include changes in production (neoliberal adjustments), State reform, current higher education policy and the deepening of that which has been identified by some Portuguese neologisms such as mercadização, mercadorização and mercantilização (approximately, marketization, commodification or commercialization) of higher education. This phenomenon presents some features common to those which occur in central countries and in the periphery of capitalism dominated by neoliberal rationality, but also reveals others, very particular and specific, that differ significantly from those present abroad. In view of this, we conclude that the question in the title of this paper - what is going to happen to community and church related higher education institutions? - must always be repeated, both to confront the management of these institutions of such recognized importance in the country and to denounce the paths followed by higher education policy in Brazil, which is quickly allowing itself to be led by the neoliberal rationality dominating the market and the State itself.

Key-words: Community institutions; Church related institutions; Higher education COMMODIFICATION; HighER EDUCATION POLICY.

Resumen Este artículo intenta contextualizar las oleadas de despidos de docentes de la UNIMEP y de otras instituciones de educación superior comunitarias y confesionales ocurridas hacia fines de 2017. Busca también demostrar que, a pesar de las especificidades propias de la gestión de las instituciones metodistas por medio de la "Red Metodista", esto forma parte de un fenómeno mucho más amplio que proviene de varios factores presentes en el país. Entre estos aparecen los cambios en la producción (ajuste neoliberal), la reforma del Estado, la política de educación superior vigente y la profundización de los fenómenos que traducen los neologismos mercadización, mercadurización y mercantilización de la educación superior. Estos fenómenos presentan algunos trazos comunes entre lo que ocurre en los países centrales y los de la periferia del capitalismo, dominados por la racionalidad neoliberal, pero también revela otros, muy particulares y propios, que difieren en forma significativa de los que tienen vigencia en el exterior. Frente a esto, se concluye afirmando que la pregunta que le da título a este texto - ¿Qué será de las instituciones comunitarias y confesionales? - debe ser siempre formulada, sea para cuestionar la gestión de estas instituciones, de tan reconocida importancia en el país, sea para denunciar los caminos seguidos por la política de educación superior en el Brasil, que está dejándose conducir en forma acelerada por la racionalidad neoliberal dominante del mercado y del propio Estado.

Palabras clave: Instituciones Comunitarias; Instituciones Confesionales; Mercantilización de la Educación Superior; Política de Educación Superior. 


\section{INTRODUÇÃO}

Há pouco mais de uma década da última grande crise vivida pela Universidade Metodista de Piracicaba (UNIMEP), que teve seu ápice na demissão de 148 docentes em 6 de dezembro de 2006, voltou a direção dessa universidade a surpreender sua comunidade e o país, em dezembro de 2017, com a demissão de outros 63 de seus docentes de graduação e pós-graduação. Todos demitidos sem justa causa.

Esse não foi um fato isolado entre as instituições congêneres - comunitárias e confessionais - nem entre as demais instituições privadas do país. Também não foi de todo imprevisível. As notícias de levas de demissões em outra instituição metodista, a Universidade Metodista de São Paulo (UMESP; São Bernardo do Campo, SP), permitiam antever o que poderia se dar também na UNIMEP. Já eram preocupantes, então, os informes a respeito da redução de suas matrículas, sobre problemas com o sistema de informação (software) contratado e, principalmente, acerca de seu déficit operacional crescente. Entre Instituições de Educação Superior (IES) privadas com fins lucrativos, ao final de 2017, o número dos docentes demitidos somava dezenas de milhares, tendo se destacado o caso, bastante divulgado na grande mídia, da demissão, numa única vez, de 1.200 docentes pela Universidade Estácio de Sá, com sede no Rio de Janeiro, a segunda maior empresa do setor, com cerca de 500 mil matrículas.

Após o espanto inicial em face do fato consumado, os envolvidos e seus próximos tenderam a imputar essa medida administrativa à recente "reforma trabalhista" (Lei n. 13.467, de 13 de julho de 2017), aprovada pelo Congresso Nacional e homologada pela Presidência da República. Entre outros disparates, essa lei flexibilizou as normas relativas à admissão e demissão de funcionários, trabalhadores, docentes incluídos, em meio à reforma de mais de 100 artigos da Consolidação das Leis do Trabalho (CLT; Decreto-Lei n. 5.452, de $1^{\circ}$. de maio de 1943). Entre suas "pérolas" destaca-se a facilitação do trabalho intermitente, sem vínculo empregatício, com valores hora/trabalho irrisórios, sem relação com os mínimos do salário mínimo e sem aquisição, pelo trabalhador, de direitos trabalhistas. Isso completava, em termos de retrocessos no campo trabalhista, o que já fora aprovado no âmbito da Lei $n$. 13.429, de 31 de março de 2017 - vista por analistas como um "cheque em branco para os empresários" - que estende a terceirização (trabalho temporário) para todas as atividades essenciais da economia, muito além do que já ocorria com as atividades ditas complementares.

Este artigo visa contextualizar esse fato - de novas levas de demissões na UNIMEP, em outras instituições comunitárias e confessionais, e nas demais IES privadas sem e com fins lucrativos - e buscar demonstrar que, apesar de especificidades próprias à gestão das instituições metodistas, via "Rede Metodista", este fato faz parte de um fenômeno muito mais amplo que decorre das mudanças na produção (ajuste neoliberal), reforma do Estado, política de educação superior vigente, assim como, do aprofundamento do que traduzem os neologismos mercadização, mercadorização e mercantilização da educação superior no país. Esse fenômeno apresenta alguns traços comuns ao que ocorre em países centrais e da periferia do capitalismo dominado pela racionalidade neoliberal, mas também revela outros, muito particulares e próprios, que diferem significativamente dos que vigem no exterior. 
Em outros termos, pretende-se mostrar como esse contexto, que se foi constituindo ao longo das últimas duas décadas, produziu as condições que estão levando a uma profunda transformação do subsistema de educação superior no Brasil, com uma acelerada e desregulada expansão da educação superior privada com fins lucrativos e consequente redução do espaço de atuação do setor privado sem fins de lucro, mormente das IES comunitárias e confessionais, tanto no número de instituições como no de matrículas. As IES públicas, em especial as federais, embora tenham apresentado crescimento expressivo quanto a unidades e matrículas nos últimos anos, até 2012/13, graças ao Reuni (Programa de Apoio a Planos de Reestruturação e Expansão das Universidades Federais - Decreto n. 6.096, de 24 de abril de 2007), viram sua proporção numérica de matrículas, no total do país, diminuir bastante, embora em escala menor do que a verificada com as IES privadas comunitárias e confessionais (vide números adiante).

Adiante-se desde logo que as ondas de demissões de docentes nas instituições comunitárias e confessionais possuem características e razões diversas daquelas das IES privadas com fins lucrativos. As demissões de docentes nas primeiras tendem a se impor, via de regra, em razão da redução do número de matrículas e, em última instância, portanto, de seu déficit operacional. As das segundas (IES privadas com fins lucrativos) correspondem à necessidade de promoção da rotatividade (turnover) de seu corpo docente, majoritariamente contratado em regime de hora/aula, cujos membros, desligados, são substituídos por outros passados apenas alguns meses (de férias ou não), com salário ou pagamento por hora/aula menor e, assim, garantir-se aumento do lucro dessas empresas e de sua competitividade no mercado.

\footnotetext{
Uma das características da precariedade das relações de trabalho é exatamente o fenômeno da alta rotatividade que, em 2013, teria alcançado, nas IES privadas (privadas e particulares), o índice de 26\% (67.200) de contratos encerrados sobre o total das funções docentes (257.480) e 23\% (60.867) novos contratos (RODRIGUES FILHO, 2015, p. 78, apud SGUISSARDI, 2017, p. 154).
}

A nova legislação trabalhista recém-aprovada deverá fazer que os cerca de $80 \%$ do corpo docente das IES privadas, que trabalham no regime de hora/aula, que eram substituídos em média a quatro anos, agora tendam a sê-lo em, talvez, até menos de três anos.

\section{Ajuste neoliberala na economia, no Estado e na sociedade}

Costuma-se situar a entrada em ação da racionalidade neoliberal na economia, no Estado e na sociedade brasileiros a partir da passagem dos anos 1980 aos anos 1990 com a disseminação e adoção dos princípios e diretrizes do denominado Consenso de Washington (1989). Era o final do Governo José Sarney (1985-1990) e início do Governo Collor de Mello (1990-1992).

Diante da crise econômica vivida então, em que se sobressaíam altíssimos índices inflacionários, o receituário do Consenso de Washington foi recebido pelas autoridades estatais e pelo grosso do empresariado como uma solução providencial. 
As dez recomendações desse Consenso, adaptadas de seus princípios originais pelo jurista Sebastião José Roque (2012), são as que seguem:

1. Disciplina fiscal - O Estado deve exercer rígido controle de seu orçamento, cortando os gastos públicos e evitando déficit orçamentário, mantendo o equilíbrio no planejamento econômico e financeiro.

2. Direcionamento dos gastos públicos - Os investimentos do Estado serão aplicados em obras e projetos que propiciem retorno e tenham efetividade, principalmente na infraestrutura, e evitar supérfluos.

3. Reforma tributária - Os tributos não devem refrear a produção e as operações internacionais, baseando-se mais nos impostos indiretos do que [n]os diretos.

4. Liberalidade financeira - Dar fim às restrições ao crédito e entidades creditícias, principalmente as internacionais, dando liberdade e equidade às organizações nacionais.

5. Taxa de câmbio - Adotar câmbio de mercado livre, evitando rígido controle pelo Poder Público, como o Banco Central do Brasil.

6. Liberalização do comércio exterior (Trade) - Redução das alíquotas de importação e estímulos à exportação, visando à globalização da economia; enfim levando o país a exportar menos e importar mais. O fator que dirige esses princípios é a globalização, vale dizer, a internacionalização da economia, com a crescente interdependência de mercados, legislação e empresas. Evitar a burocracia.

7. Liberalização do capital externo - Eliminação de todos os entraves ao ingresso de capitais estrangeiros e à instalação de agências bancárias; implantação de empresas.

8. Privatização de empresas - Evitar a instalação de empresas estatais e eliminar as já existentes, passando-as à iniciativa privada. [...]

9. Desregulamentação da economia - Evitar a monitoração da economia por meio de leis regulamentadoras e controles do processo econômico. Adotar, de forma mitigada, o regime do laissez faire. Adotar orientação nas relações trabalhistas, com maior flexibilização das leis do trabalho, com a rigidez das formas de contratação.

10. Respeito à propriedade intelectual - É o respeito às marcas, patentes, invenções modelos, e outros bens de propriedade intelectual, que no Brasil é chamado de Direito da Propriedade Industrial. Combater a pira[ta]ria, principal agressão à propriedade intelectual das empresas. Fruto dessa política, por exemplo, é a Lei dos Cultivares, promulgada no Brasil e a Lei da Propriedade Industrial, a Lei 9.279/96.

Esse receituário consagra inegavelmente o mercado (livre iniciativa) e a livre concorrência, "definida como relação de desigualdade entre diferentes unidades de produção ou 'empresas'. Por conseguinte, construir o mercado implica fazer valer a concorrência como norma geral das práticas econômicas", como afirmam Pierre Dardot e Christian Laval (2016, p. 377). ${ }^{1}$

A concorrência que, desde o início do liberalismo, sempre esteve no centro do processo econômico, passa, com o neoliberalismo, a exercer um papel muito mais central, não somente no mercado, nas relações capital-trabalho, mas também nas instâncias do Estado, nos campos da cultura, ciência, saúde e educação [ver sobre o papel da concorrência no neoliberalismo a obra, de Pierre Dardot e Christian Laval, A Nova Razão do Mundo - Ensaio sobre a sociedade neoliberal (São Paulo: Boitempo, 2016)]. 
A observância dessas recomendações pelos países subdesenvolvidos ou em desenvolvimento, aos quais se destinavam, tornava-se condição básica para empréstimos de órgãos financeiros internacionais, como o FMI e outros.

Não demoraram a ser adotadas por diversos países. No caso do Brasil, como afirma Roque:

O discurso de posse do Presidente Fernando Collor revelou total enquadramento de seu programa de governo aos dez princípios do Consenso; o discurso de posse do Presidente Fernando Henrique Cardoso foi bem semelhante. Os governos que se seguiram não se pronunciaram a este respeito, mas a política econômica seguida por eles revelou sua integração aos dez princípios. Bastaria citar um só exemplo: a maioria das empresas estatais brasileiras foram privatizadas nos termos do Consenso de Washington. (2012)

Observe-se que entre o curto mandato de Fernando Collor (dois anos) e o de Fernando H. Cardoso (FHC) ocorreu o mandato-tampão de Itamar Franco (1993-1994), que teria produzido certo hiato na adoção dessas recomendações do Consenso de Washington.

Embora seja discutível a afirmação de que a política econômica seguida pelos governos posteriores aos de Collor e FHC esteve integrada aos dez princípios mencionados, o exemplo citado - da privatização da maioria das empresas estatais - retrata perfeitamente a observância da recomendação de n. 8 , isto é, da privatização, durante os dois mandatos de FHC, a preços módicos e subsidiados com empréstimos do BNDES, de grande número de importantes estatais, como a Companhia Siderúrgica Nacional e a Vale do Rio Doce. ${ }^{2}$

Durante os mandatos de FHC, além da privatização das estatais, muitas dessas recomendações foram seguidas, pelo menos parcialmente, caracterizando-se seu governo como de visada estritamente neoliberal.

No caso da educação superior, a sua transformação nos termos neoliberais - para usar alguns neologismos que traduzam os novos fenômenos na área, como mercadização, mercadorização e mercantilização - vai se dar na esteira da reforma do Estado. Reforma que visa adequar o aparelho do Estado às novas exigências postas pelo ajuste neoliberal, via adoção das diretrizes definidas pelo Consenso de Washington.

Essa reforma do aparelho do Estado seria qualificada como gerencial. O Estado moderno - então visto como socialdemocrata, porque a denominação de neoliberal não era bem-vista - era pensado como constituído de duas esferas básicas: "um núcleo burocrático ${ }^{3}$ voltado para a consecução das funções exclusivas do Estado, e um setor de serviços sociais ${ }^{4}$ e de obras de infraestrutura" (PEREIRA, 1995, p. 7).

2 Durante os mandatos de Lula da Silva e Dilma Rousseff (2003 a 2016) nenhuma empresa estatal foi privatizada.

3 "O núcleo burocrático corresponde ao poder legislativo, ao poder judiciário, e, no poder executivo, às forças armadas, à polícia, à diplomacia, à arrecadação de impostos, à administração do Tesouro público, e à administração do pessoal do Estado. Também fazem parte desse núcleo as atividades definidoras de políticas públicas existentes em todos os ministérios. O núcleo burocrático está voltado para as funções de governo, que nele se exercem de forma exclusiva: legislar e tributar, administrar a justiça, garantir a segurança e a ordem interna, defender o país contra o inimigo externo, e estabelecer políticas de caráter econômico, social, cultural e do meio ambiente" (PEREIRA, José B., 1995: 7).

4 O setor de serviços faria parte do Estado, mas não seria governo. Suas funções: as de “...cuidar da educação, da pesquisa, da saúde pública, da cultura, e da seguridade social. São as funções que também existem no setor privado e no setor público não-estatal das organizações sem fins lucrativos” (PEREIRA, José B., 1995, p. 7). 
O núcleo burocrático teria como traço essencial a segurança das decisões tomadas; o setor de serviços sociais, a qualidade dos serviços prestados aos cidadãos. O primeiro teria como princípio a efetividade; o segundo, a eficiência, isto é, a ótima relação entre qualidade e custos dos serviços (PEREIRA, 1995: 7).

É sintomática e significativa a afirmação dos defensores da Reforma do Estado de que a "eficiência, agilidade, etc., dos serviços do Estado deveriam ser semelhantes às do setor privado" (SILVA JÚNIOR; SGUISSARDI, 1997, p. 12). Com isso, se levava o interlocutor a pensar em formas de administração "mais flexíveis do que as adotadas no núcleo burocrático da administração direta" e que, aquelas, seriam próprias das organizações sociais em que se propunha transformar as universidades federais, por exemplo (PEREIRA, 1995, p. 8).

Esse discurso, principalmente em relação ao setor de serviços, preparava o terreno para desestatizar/privatizar os serviços públicos de saúde e de educação. O setor de serviços faria parte do Estado, mas não do governo. Seriam serviços competitivos idênticos aos oferecidos pelo setor privado e por organizações não governamentais.

A ideia de reduzir o custo do Estado e de torná-lo guardião da propriedade privada e garante da concorrência entre as empresas do mercado, e um "Estado Avaliador e Regulador", via agências reguladoras, estava na ordem do dia nos inícios do e durante o Governo FHC, de 1995 a 2002.

Destituir o Estado de suas funções de cunho social, predominantes durante sua fase socialdemocrata na Europa e, sob certos aspectos, na nacional-desenvolvimentista no Brasil, foi o modo de torná-lo funcional à adoção do receituário do Consenso de Washington, isto é, ao ajuste neoliberal.

Se não se avançou mais, quanto à privatização das empresas e entidades estatais, no campo da educação superior, foi porque a Constituição Federal de 1988 o impedia. Contudo, como se viu a posteriori, nada impedia que o governo de turno sustasse toda a expansão das IES federais, congelasse o número de professores e seus respectivos salários durante a maior parte do período 1995-2002 e reduzisse significativamente o montante de funcionários técnico-administrativos dessas instituições, como de fato se fez.

Os recursos totais destinados ao conjunto das IES federais de 1995 a 2003 (nesse caso, orçamento aprovado em 2002) se reduziram em cerca de $30 \%$, isto é, de um montante de $\mathrm{R}$ \$ 3.219 milhões para R \$ 2.028 milhões (valores de janeiro de 2006), segundo Sguissardi e Silva Júnior $(2009$, p. 81).

A redução do número de funcionários técnico-administrativos das IES federais do Sudeste, de 1995 a 2003, foi de 36\%. O número de professores permaneceu relativamente estável, mas nesse período a redução salarial variou de cerca de $15 \%$ para os professores auxiliares de ensino a cerca de $20 \%$ para os professores doutores (titulares e adjuntos), segundo ainda dados de Sguissardi e Silva Júnior (2009, p. 88-89).

\section{Políticas Públicas de EducaÇão Superior ajustadas à Racionalidade NeOLiberal}

O tratamento dado pelo Governo FHC às IES federais vai se somar às medidas legislativas e de estímulo que atingirão o setor privado da educação superior, especialmente com 
os Decretos 2.207/97 e 2.306/97, para conformar o que se pode chamar de política pública de educação superior à racionalidade neoliberal.

A Constituição Federal de 1988 (Artigos 150 e 213) já previa a possibilidade de existirem IES privadas particulares ou com fins lucrativos. A Lei de Diretrizes e Bases da Educação Nacional (Lei 9.394/96, artigo 20) manteve essa previsão. Mas é apenas com esses decretos, de 1997, normatizadores do artigo 20 da última Lei, que se produziu a grande mudança no subsistema de educação superior no país e se desencadeou o que se denomina de processo de mercadorização/mercantilização do setor privado desse subsistema.

Até então, especialmente até o Golpe Civil-Militar de 1964, além das IES públicas (federais e estaduais), predominavam as IES privadas confessionais e/ou comunitárias, e privadas formalmente sem fins lucrativos. Foi, especialmente, com o artigo $7^{\circ}$. do Decreto n. 2.306, de agosto de 1997, que se completou a definição legal da educação superior também como "negócio", não mais como um direito, mas como um "serviço educacional" comercializável:

É a abertura ao mercado educacional, ao que vinha sendo proposto pelo AGCS [Acordo Geral de Comércio e Serviços] da OMC [Organização Mundial do Comércio], isto é, a liberalização dos "serviços" de educação superior como se comerciais fossem, como mercadoria de lucro, commodity, educação-mercadoria de interesse dos fundos de investimento de private equity, dos empresários da educação. (SGUISSARDI, 2014, p. 135). ${ }^{5}$

O impacto dessa mudança ou concessão legal foi de tal ordem que, no ano de 2016, passadas menos de duas décadas, as IES privadas com fins lucrativos já somavam 1.052 ou $44 \%$ do total de 2.407 IES do país, entre as quais uma dezena - a maioria delas com capital aberto e ações em Bolsa de Valores - detém quase 50\% das 6,5 milhões de matrículas privadas que correspondem a mais de $75 \%$ dos cerca de 8 milhões de matrículas públicas e privadas do país.

Por sua vez, o número de instituições e de matrículas das IES comunitárias e confessionais que, em 1999, era de 34,5\% (379) e 37\% (886.651), respectivamente, em 2010, tinha se reduzido a 10,5\% $(250)^{6}$ e $11 \%(600.501),{ }^{7}$ respectivamente (BRASIL, MEC/INEP. Sinopse Estatística da Educação Superior, 2011, apud SGUISSARDI, 2014, p. 199 e 201).

5 O termo commodity, em termos estritamente econômicos, significa qualquer mercadoria em estado bruto ou produto primário, de origem agropecuária, vegetal ou mineral - como soja, trigo, café, açúcar, cada tipo de minério etc. - produzido em larga escala, com características físicas homogêneas e cujos preços se submetem à oferta e procura, isto é, às oscilações do mercado internacional (ver BIANCHETTI; SGUISSARDI, 2017, p. 15).

Por fundos de private equity entendem-se "os que se investem diretamente em empresas já consolidadas, visando geri-las, reestruturar sua 'governança', prepará-las para a oferta inicial de ações (IPO), e operar o desinvestimento a longo prazo. Podem atuar em empresas nos processos de fusão e compra. [...] Os recursos de private equity podem ser investidos em empresas de capital aberto, 'para alterações financeiras, operacionais ou estratégicas, visando a um novo posicionamento no mercado"' (SGUISSARDI, 2014, p. 164, nota 125).

6 Estimativa a partir da taxa de evolução anual no triênio 2006-2009.

7 IDEM. 
Involução de -34\% para as instituições e - $32 \%$ para as matrículas. ${ }^{8}$

As demais IES privadas, isto é, as com fins lucrativos e as sem fins lucrativos, estas sem contar as confessionais e comunitárias, tiveram um crescimento acelerado que apresentou os seguintes dados: em 1999, as IES somavam 48\% (526) do total (1.097) e, em 2010, 77,8\% $(1.850)^{9}$ do total (2.378), isto é, um crescimento percentual no período de $252 \%$.

Algo similar ocorreu com as matrículas das IES privadas (afora as comunitárias e confessionais): em 1999 sua participação no total de 2.369 .945 era de $27,5 \%$ ou 651.362 ; em 2010 , de um total de 5.449 .120 matrículas, sua participação já era de $62 \%$ ou $3.386 .923 .{ }^{10}$

O número das IES públicas, nesse mesmo período, diminuiu seu percentual de participação no total de $17,5 \%$ (192) para $11,7 \%$ (278). As matrículas das IES públicas, nesse período, reduziram seu percentual no total de $35,1 \%$ (832.022) para $26,8 \%(1.461 .696)$.

Tabela 1 - Evolução do número de instituições e de matrículas de educação superior por categoria administrativa (público e privada) - 2010-2015.

\begin{tabular}{c|c|c|c|c|c|c|c|c|c|c}
\hline \multirow{2}{*}{ Ano } & \multicolumn{5}{|c|}{ Número de Instituições } & \multicolumn{5}{c}{ Número de Matrículas } \\
\cline { 2 - 11 } & Total & Públ. & $\%$ & Priv. & $\%$ & Total & Públ. & $\%$ & Priv. & $\%$ \\
& & & & & & & & \\
& & & & & & mil) & $(\mathrm{mil})$ & & $(\mathrm{mil})$ & \\
\hline 2010 & 1.097 & 192 & 17,5 & 905 & 82,5 & 5.449 & 1.461 & 26,8 & 3.987 & 73,2 \\
\hline 2015 & 2.364 & 295 & 12,5 & 2.069 & 87,5 & 8.027 & 1.952 & 24,3 & 6.075 & 75,7 \\
\hline 2016 & 2.407 & 296 & 12,3 & 2.111 & 87,7 & 8.048 & 1.990 & 24,7 & 6.058 & 75,3 \\
\hline$\% 2010-2015$ & 115,5 & 53,6 & - & 128,6 & - & 47,3 & 33,6 & - & 52,4 & - \\
\hline$\% 2010-2016$ & 119,4 & 54,2 & - & 133,3 & - & 47,7 & 36,2 & - & 51,9 & - \\
\hline \hline
\end{tabular}

Fonte: BRASIL. MEC/Inep. Sinopse Estatística da Educação Superior, 2010 e BRASIL/MEC/Inep. Censo da Educação Superior, 2016.

Observando-se a Tabela 1, destacam-se alguns dados que confirmam as tendências da política de educação superior de 2010 a 2016: 1) O número de IES públicas (federais,

8 Os dados da evolução do número de IES comunitárias e confessionais e do montante de suas matrículas ao longo dos últimos anos, desde 2009, não são conhecidos, porque, desde 2010, o Censo da Educação Superior do INEP/MEC adotou outra forma de apresentar os dados. Enquanto de 1999 a 2009, os dados, para instituições e matrículas, eram classificados segundo a categoria administrativa como públicas (federais, estaduais e municipais) e privadas (confessionais/comunitárias e particulares), a partir de 2010, essa classificação assim se apresenta: públicas (federais, estaduais e municipais) e privadas. Estas, nas sinopses públicas, não são separadas como na classificação anterior. Nos microdados que não são divulgados ao público em geral, apenas se faz a distinção entre as privadas sem fins lucrativos e com fins lucrativos, englobando no conjunto das primeiras as comunitárias e confessionais.

9 Estimativa a partir da taxa de evolução anual no triênio 2006-2009.

10 IDEM. 
estaduais e municipais) cresceu $54,2 \%$ contra $133,3 \%$ do das IES privadas. Neste caso, com muita probabilidade o peso maior se deva às privadas com fins lucrativos, dando continuidade ao que ocorreu de 1999 a 2009. 2) O mesmo movimento, embora em proporção menor, se verifica em relação ao montante de matrículas: $36,2 \%$ de aumento no número das matrículas em IES públicas contra 51,9\% no das matrículas em IES privadas. 3) Os dados do item 1 resultaram na redução do percentual de instituições públicas (de 17,5\% para $12,3 \%$ ) e no consequente aumento do das instituições privadas (de 82,5\% para 87,7\%). 4) Em grau menor, se reduziu o número de matrículas das IES públicas (26,8\% para $24,7 \%)$ em relação ao número crescente das matrículas das IES privadas $(73,2 \%$ para $75,3 \%)$.

Observa-se um fenômeno raro na história da evolução das matrículas da educação superior nas últimas décadas: um aumento proporcionalmente maior das matrículas públicas em relação às privadas do ano de 2015 a 2016. Isso, provavelmente, se deva às mudanças ocorridas, via Portarias ministeriais (N. 21 e 23 de dezembro de 2014), nas exigências quanto ao direito de usufruto pelos estudantes das IES privadas ao FIES (Fundo de Financiamento Estudantil) que chegou a beneficiar cerca de 35\% do total de matrículas desse setor. Durante o primeiro semestre de 2015 as ações dos principais grupos educacionais que atuam na Bovespa sofreram uma desvalorização de cerca de $30 \%$, dada a previsão de uma redução significativa de candidatos habilitados ao empréstimo do FIES, isto é, que obtivessem no mínimo nota 4 no ENEM e nota diferente de zero na prova escrita, exigências dessas Portarias.

\section{MercadizaÇÃo, MERCAdorizaÇão E MERCANTILIZaÇÃo}

Alguns traços marcantes do ajuste das políticas de educação superior à racionalidade neoliberal são hoje traduzidos, à falta de vocábulos usuais que retratem esta nova realidade, por alguns neologismos que já estão se tornando frequentes em línguas modernas como inglês, espanhol e português. São elas, em português, mercadização, mercadorização e mercantilização. Outros também já têm sido utilizados, como comercialização e commodityzação. São comuns, igualmente, expressões como mercado educacional, mercado universitário, setor educacional da economia ou do mercado de capitais ou, ainda, da Bolsa de Valores. Em todos esses termos e expressões está subjacente aquela "qualidade" essencial ao neoliberalismo que é a concorrência.

Ainda em 2006, na véspera do ano de abertura de capital e entrada na Bolsa de Valores de São Paulo (2007) dos quatro primeiros grupos do mercado educacional brasileiro - Kroton, Anhanguera, Estácio e SEB (Sistema Educacional Brasileiro) - que assim procederam, o especialista chileno e colaborador do Banco Mundial José Joaquim Brunner, em estudo sobre os "mercados universitários", destacava um fenômeno que vinha ocorrendo nos países centrais e em alguns da periferia do mundo capitalista. Esse fenômeno consistia no deslocamento da coordenação dos sistemas de educação superior - "em geral, a esfera pública" - para o mercado:

...isto é, para arranjos institucionais que forçam as universidades a competir entre 
elas por alunos, pessoal acadêmico e reputações, e a financiar suas atividades por meio de recursos obtidos - crescentemente de maneira competitiva - de uma diversidade de fontes fiscais e privadas. Este deslocamento é examinado na literatura anglo-saxônica sob o nome de marketization que no castelhano traduz-se (em má tradução) por mercadização, ainda que se empreguem termos tais como privatização, comercialização e mercantilização (BRUNNER, 2006, p. 3).

Como já afirmado (SGUISSARDI, 2016), Brunner não se referia a grupos empresariais, companhias e players, que, atuam no campo educacional, abrem seu capital e passam a auferir vantagens com a valorização de suas ações no mercado de capitais. Esse fenômeno irá traduzir-se muito melhor por termos como mercadorização e mercantilização. $\mathrm{O}$ termo ou neologismo que Brunner prefere utilizar - mercadização - parece adequar-se melhor a mudanças no papel dos governos em relação às próprias instituições estatais/públicas em suas diferentes esferas e às instituições privadas sem fins lucrativos, entre as quais as comunitárias e confessionais que, diante dos avanços do ajuste neoliberal, são induzidas ou orientadas a seguir as normas da concorrência e inovação próprias das empresas privadas do mercado em geral.

Tem ocupado lugar de destaque no discurso oficial e também no do mercado a aposta na concorrência, na competitividade da economia. São redesenhados os mecanismos de gastos públicos e, para tanto, adotados e seguidos os mecanismos de tipo mercado. A busca de maior eficiência tem levado os governos dos países centrais e da periferia e semiperiferia a reduzir os gastos com as IES públicas e a estimular e subsidiar as IES privadas, transferindo, inclusive, parte dos custos da educação pública e, em especial, da educação privada para os alunos e suas respectivas famílias.

Segundo Brunner, caracterizam ainda a mercadização das IES estatais/públicas nos países centrais e nos da periferia e semiperiferia, embora em graus e formas distintos:

a) A submissão da educação superior a um regime que the impõe eficiência, efetividade e value for money por métodos externos de garantia da qualidade e outros meios de accountability.

b) Fundos públicos declinantes para subsidiar mensalidades e o custo dos serviços, ao lado da exigência de satisfação de uma crescente demanda por educação superior com menor inversão pública.

c) A exigência de gestão das universidades públicas segundo princípios ou métodos próprios da gestão privada e predomínio de enfoques empresariais e de management na educação superior.

d) A demanda por diversificação das fontes de financiamento das instituições combinada com a redução da responsabilidade prioritária do Estado em relação à educação pública.

e) A privatização da educação superior, tanto mediante a terceirização dos serviços e, inclusive, áreas de estudo, quanto mediante o incentivo da competição entre instituições públicas. 
f)) Reformas curriculares orientadas para o mercado; ênfase na pesquisa aplicada e vínculo das universidades com as empresas; maior preocupação com os temas da propriedade intelectual (patentes) e prioridade à pesquisa que conduza ao desenvolvimento e comercialização de produtos (BRUNNER, 2006, p. 22-23).

Ainda de acordo com esse autor, outros traços podem ser acrescentados a esses como a perda do conceito de bem público, tradicionalmente aplicado à educação superior estatal/ pública, a erosão da cultura democrático-colegial das instituições estatais/públicas e a eliminação das áreas de estudo e pesquisa distantes do mercado, como artes e humanidades etc. (IBIDEM, p. 23-24).

O que vai ocorrer, no caso do Brasil, a partir dos Decretos n. 2.207/97 e 2.306/97, com a legalização do lucro nas IES - que fará do direito à educação um mero serviço comercial, do ensino uma espécie de commodity ou mercadoria, ${ }^{11}$ da sua oferta um efetivo negócio e das instituições de ensino verdadeiras organizações mercantis, além de empresas de capital aberto com ações em Bolsa de Valores - será melhor traduzido pelos termos mercadorização ou mercantilização.

Em outras palavras:

...no caso da mercadização, são as regras do mercado que estariam cada vez mais a guiar as ações das IES estatais/públicas e assemelhadas (privadas sem fins lucrativos). No caso brasileiro, por exemplo, possivelmente todas as IES estatais/públicas já contem com fundações de apoio institucional (FAI), entidades privadas. A USP, exemplo específico, já há mais de 10 anos dispunha de mais de três dezenas dessas fundações, que oferecem, entre outros, os famosos cursos de MBA, a alto custo para os alunos, garantidores de vultosas complementações salariais aos seus docentes em geral integrantes do quadro permanente de professores da universidade.

No caso da mercantilização, não são apenas as regras do mercado que orientam parte importante da vida institucional, mas são a própria educação transformada em mercadoria e o objetivo do lucro antes de tudo, inclusive via valorização acionária, no caso das empresas de capital aberto e ações em bolsa de valores, que comandam, de modo direto e indireto, o cotidiano dessas instituições ou organizações $^{12}$ (SGUISSARDI, 2016).

Como se verifica, as políticas de educação superior estão, assim como o Estado, conformando-se cada dia mais à racionalidade neoliberal, que Christian Laval define como sendo "a um só tempo, a lógica normativa da concorrência, o modelo da empresa privada e o poder normatizador da finança sobre todas as atividades" (2016). E acrescenta:

11 Segundo Oliveira (2009, p. 953), citando Tom Bottomore, mercadoria é "tudo o que possa ser "comprado ou vendido' numa perspectiva de acumulação de capital". Esse autor conclui em seu estudo: "À luz dos dados aqui apresentados, resta pouca dúvida de que a educação tenha se transformado em importante mercadoria" (2009, p. 953).

12 É sempre oportuno recorrer à discussão iniciada por Freitag (1996) no Canadá, e retomada por Marilena Chauí (2003) no Brasil, sobre a distinção entre instituição social e organização social. 
Esta racionalidade neoliberal pode definir-se como um sistema normativo ou uma lógica geral que impõe, universalmente, um modelo de mercado pelo qual as instituições e os indivíduos são postos em concorrência; de modo que cada entidade e cada indivíduo deve comportar-se como uma empresa numa situação de mercado (IBIDEM).

Laval chama também atenção para o papel do Estado nesse âmbito: "Esta racionalidade domina o Estado, preside sua metamorfose, é carregada por ele e projetada para a sociedade que o Estado busca reformar". Vê o papel do Estado como determinante, "não, como ingenuamente se acreditava, como freio, mas, ao contrário, como acelerador desta mutação. [...] É ele o principal agente da guinada do campo do conhecimento rumo ao mercado" (IBIDEM).

Pode-se reafirmar aqui a dupla face ou a dupla polaridade do Estado, como arena de contradições e conflitos permanentes, no capitalismo, dos interesses públicos versus interesses privado-mercantis. Confronto em que tendem a predominar os últimos, no caso, quando se visualiza o que está ocorrendo no âmbito da educação superior como parte do Estado em sentido amplo, como diria Gramsci (SGUISSARDI, 2014, p. 17-20).

\section{CONSIDERAÇõES FINAIS:}

\section{Desafios de sobrevivência das IES Comunitárias e Confessionais e da PRÓPRIA UNIMEP}

A involução dos números de instituições e de matrículas revelada pelos Censos de Educação Superior (do Inep/MEC) de 1999 a 2009 e as crises enfrentadas, seja pelas instituições metodistas, seja pelas demais instituições comunitárias e confessionais, nos anos recentes, fatos bastante noticiados pela mídia, estão comprovando a hipótese, apenas aparentemente pessimista, de que essas instituições de educação superior tenderão a reduzir ainda mais seu espaço de atuação nesse subsistema no país em futuro próximo.

A concorrência, em especial com os grupos empresariais que podem abrir o capital e auferir ganhos financeiros em bolsa de valores e ter como sócios fundos de investimento de private equity nacionais e principalmente transnacionais - como é o caso da Kroton, Estácio, Ser Educacional, Anima, DeVry, Carlyle e outros - torna-se uma batalha de improvável sucesso para as IES comunitárias e confessionais, a não ser como exceção.

Em 2012 (p. 82), Fávero e Sguissardi já mostravam a gravidade dessa situação ao escreverem:

A facilidade que as empresas de capital aberto atuantes no campo educacional têm de ampliar seu capital via bolsa de valores - quando investidores privados, pessoas físicas e principalmente jurídicas, do mundo inteiro podem comprar suas ações - está significando uma competição extremamente desigual com as IES privadas sem fins lucrativos, como as comunitárias e confessionais e mesmo particulares de propriedade familiar, sem capital aberto, o que está levando 
à falência ou à redução drástica do número destas IES e de sua capacidade de atrair e manter estudantes [...]. Enquanto as comunitárias e confessionais e outras precisam manter-se quase exclusivamente com os recursos advindos das mensalidades de seus alunos, afora os eventuais auxílios do fundo público que beneficia em especial os Programas de Pós-Graduação stricto sensu, as empresas de capital aberto, detentoras de centenas de IES, podem suprir a maior parte dos custos de manutenção de suas instituições com recursos captados no mercado de ações (grifos do autor).

Além do que, quando se examinam os números relativos à participação de estudantes nos programas de bolsas, como o Prouni (Educação para todos), e de empréstimos, como o Fies, constata-se que em geral é o corpo discente das IES dos grandes grupos empresariais, com grande valor de mercado, que conta com os maiores percentuais de beneficiários dessas bolsas e desses empréstimos.

Outro fenômeno que se apontava, em 2012, era a desnecessidade de altos escores nas avaliações nacionais para as instituições privadas com fins lucrativos competirem no mercado:

Ademais, dada a potencial grande expansão do mercado educacional nos próximos anos - hoje, no Brasil, apenas cerca de $15 \%$ dos jovens de 18 a 24 anos frequentam a educação superior; enquanto países limítrofes na América Latina já alcançam índices duas ou três vezes maiores - e, portanto, com muito pequena competição no mercado, essas empresas de capital aberto não necessitam apresentar a performance e qualidade das demais empresas de capital aberto, com capital acionário na Bolsa de Valores, para atraírem investidores (FAVERO; SGUISSARDI, 2012, p. 82).

Então também se enfatizava a tendência já muito presente à monopolização desse nível de educação via empresas de capital aberto:

Monopolização que pode significar também internacionalização e perda da soberania nacional sobre o sistema de educação superior, pela interferência na propriedade e gestão dessas empresas de capital aberto por fundos financeiros internacionais, como é o caso do Grupo Laureate International Universities controladora da Universidade Anhembi Morumbi (UAM) e mais uma dezena de outras IES (IBIDEM).

Entre as conclusões e recomendações deste artigo, chamava-se a atenção para o fato de que era chegada a hora de os membros da comunidade acadêmico-científica atentar para a situação do setor comunitário e confessional que, após haver alcançado significativa participação no cenário brasileiro (34\% das IES e 37,4\% das matrículas) em 1999, "hoje estar reduzido a cerca de $10 \%$ do total e, caso continue a redução dos últimos anos ( $-30 \%$ de 1999 a 2010), a ver ainda mais diminuída sua participação" (IDEM, p. 84).

A pergunta do título deste texto - o que será das instituições de educação superior comunitárias e confessionais? - precisa ser sempre reposta, seja para questionar a gestão 
dessas instituições de tão reconhecida importância no país, seja para denunciar os caminhos que estão sendo seguidos pela política de educação superior no Brasil, que está celeremente se deixando conduzir pela racionalidade neoliberal que já domina o mercado e o próprio Estado.

\section{REFERÊNCIAS}

BIANCHETTI, L.; SGUISSARDI, V. Da Universidade à Commoditycidade - ou de como e quanto, se a educação/formação é sacrificada no altar do mercado, o futuro da universidade se situaria em algum lugar do passado. Campinas, SP: Mercado das Letras, 2017.

BRUNNER, J. J. Mercados universitários: ideas, instrumentos y seis tesis em conclusión. Santiago, Cl., mar. 2006. Disponível em: http://www.brunner.cl/wp-content/ uploads/2012/12/\%C2\%A0MERCADOS-UNIVERSITARIOS_2006.pdf Acesso em $30 / 07 / 2014$.

DARDOT, P.; LAVAL, C. A nova razão do mundo: ensaio sobre a sociedade neoliberal. São Paulo: Boitempo, 2016.

FAVERO, M. de L. de A.; SGUISSARDI, V. Quantidade/qualidade e educação superior. Revista Educação em Questão, Natal, v. 42, n. 28, p. 61-88, jan./abr. 2012.

LAVAL, C. Néolibéralisme, capitalisme et connaissance. Conferencia. Montevideo, Udelar, Jornada de Reflexión sobre tendencias en la Educación Superior - Educación Superior en el siglo XXI: bien público o mercancía? 24 de octubre 2016.

OLIVEIRA, R. P. de. A transformação da educação em mercadoria no Brasil. Educ. Soc., Campinas, v. 30, n. 108, p. 739-760, out. 2009.

PEREIRA, L. C. B.r. (1995). A Reforma do Aparelho do Estado e a Constituição Brasileira. (Conf. no Seminário sobre Reforma Constitucional, patrocinado pela Presidência da República, janeiro de 1995, revisada em abril/95.)ROQUE, S. J. O Consenso de Washington fixou nossa diretriz econômica. Disponível em http://www.conteudojuridico.com.br/ artigo,o-consenso-de-washington-fixou-nossa-diretriz-economica, 37728.html. Acesso em $16 / 04 / 2018$.

SGUissardi, V. Estudo Diagnóstico da Política de Expansão da (e Acesso à) Educação Superior no Brasil - 2002-2012. Brasília: Edital N. 051/2014 SESU; Projeto de Organismo Internacional - OEI; Projeto OEI/BRA/10/002, 2014 [ㄴinks].

. Mercadização/mercantilização - Desafios para a missão das Instituições de Educação Superior. Disponível em: http://www.aforges.org/wp-content/uploads/2016/12/Valdemar-Sguiss-Mercadizac a o-mercantilizac_a o-Texto-Mesa.pdf 
. Trabalho docente na educação superior no Brasil: heterogeneidade, insegurança e futuro incerto. Integración y conocimiento, v. 2, n. 2, p. 142-162, 2017.

. SILVA JÚNIOR, J. dos R. Trabalho intensificado nas federais - Pós-Graduação e Produtivismo Acadêmico. São Paulo: Xamã, 2009.

SILVA JÚNIOR, J. dos R.; SGUISSARDI, V. Reforma do Estado e Reforma da Educação Superior no Brasil. In: SGUISSARDI, Valdemar (Org.). Avaliação Universitária em Questão - Reformas do Estado e da Educação Superior. Campinas, SP: Autores Associados, 1997, p. 7-41.

\section{DAdOS DO AUTOR}

\section{VALDEMAR SGUISSARDI}

Bacharel e licenciado em Filosofia pela Fidene (atual Universidade de Ijuí - Unijuí). Mestre e doutor em Ciências da Educação pela Universidade de Paris-X (Nanterre, França). Professor titular aposentado da Universidade Federal de São Carlos (UFSCar). Professor aposentado da Universidade Metodista de Piracicaba (Unimep). Publicou 15 livros e cerca de uma centena de capítulos de livros e artigos em periódicos da área sobre educação superior. Dentre os livros: 1) Universidade, Fundação e Autoritarismo - o caso da UFSCar; Avaliação Universitária em Questão (org.); Universidade Brasileira no Século XXI - Desafios do presente; 2) Em coautoria com João dos R. Silva Júnior: Novas Faces da Educação Superior e Trabalho intensificado nas Federais: pós-graduação e produtivismo; 3) Em coautoria com Lucídio Bianchetti: Da Universidade à Commoditycidade; 4) Coorganizado com Lucídio Bianchetti: Dilemas da Pós-Graduação: gestão e avaliação. Em consultoria para o Conselho Nacional de Educação, em 2014: "Estudo Diagnóstico da Política de Expansão da (e Acesso à) Educação Superior no Brasil - 2002-2012”. Orientou 32 mestres e 18 doutores na UFSCar e na Unimep, de 1980 a 2010.

Currículum Lattes: http://buscatextual.cnpq.br/buscatextual/visualizacv do? id $=\mathrm{K} 4788657 \mathrm{P} 1$

Submetido em:10-5-2018

Aceito em: 23-8-2018 